\section{Política e estética na tropicália}

\section{Politics and aesthetics in tropicália}

DUARTE, Pedro. Tropicália ou Panis et Circensis. Rio de Janeiro, Cobogó, 2018. 176 páginas.

\section{Rafael Marino \\ https://orcid.org/0000-0002-2659-6434}

Universidade de São Paulo (USP), São Paulo - SP, Brasil. E-mail: rafael.marino50@gmail.com

DOI: $10.1590 / 3510201 / 2020$

Passados cinquenta anos do chamado tropicalismo ou, como preferiria um de seus criadores mais conhecidos, da tropicália (Veloso, 2017, p. 51), o debate sobre sua constituição artística, características políticas e consequências socioculturais ainda permanece aquecido e polêmico nas ciências humanas em geral e nas ciências sociais em particular. A começar pelo seu próprio caráter artístico e político: seria um movimento (Dunn, 2009; Favaretto, 2007)? Um momento (Süssekind, 2007)? Estaria à direita, vinculado esteticamente ao projeto da ditadura (Tinhorão, 1991)? Ou à esquerda? $\mathrm{Na}$ esquerda do espectro, ligou-se à guerrilha (Polari, 1982; Ridenti, 2014)? Ou espraiou-se politicamente em direção a noçóes novas, à maneira da rebeldia (Hollanda e Gonçalves, 1982) e da chamada nova esquerda (Coelho, 1989)? Por último, não se constituiria uma visão mais apurada olhá-lo como ambíguo, entre a crítica e a integração sistêmica (Schwarz, 2008, 2012b)?

Sem necessariamente responder diretamente essas questóes, o livro aqui em tela, de Pedro Duarte, traz em sua exposição ideias e interpretações valiosas ao estudo nâo só do disco-manifesto coletivo de $1968,{ }^{1}$ mas também à tropicália como um todo e também de seu pensamento político. Ou, como escreveu Duarte (2014) em sua obra sobre o modernismo, seu projeto ideológico. A obra fora lançada pela editora carioca Cobogó, responsável pela instigante coleção "O livro do disco", a qual conta com obras que exploram desde o disco Refavela, de Gilberto Gil, até Unknown pleasures, da banda inglesa Joy Division.
É interessante notar que, desde o início do livro, o filósofo carioca, mesmo que com especificidades, coloca-se num sentido interpretativo mais geral, formalizado por autores como Silviano Santiago (1977, 1982), Gilberto Vasconcellos (1977) e Favaretto (2007). Estes pensavam que boa parte da tradição intelectual brasileira não conseguiria entender a vanguarda em questáo por dois motivos: em primeiro lugar, os tropicalistas formulariam um retrato em movimento, múltiplo, estilhaçado e aberto do país, enquanto aquela tradição teria em vista uma imagem estática da nação. Em segundo lugar, a lógica alegórica e baseada no choque da tropicália não poderia ser apreendida por um pensamento imantado pelo progresso ou pelo modo de pensar dialético. ${ }^{2}$

Ainda quanto aos direcionamentos interpretativos de Duarte, veem-se quatro outros caminhos importantes que devem ser aqui assinalados. Como primeiro elemento e seguindo o argumento do autor, a tropicália deve ser entendida como um movimento que migrou da música para outras searas da arte, contagiando-as. Nesse ínterim, é importante lembrar que o nome do movimento viera, conforme aponta Veloso (2017, p. 51), de uma sugestáo do cineasta Luís Carlos Barreto à música de abertura, gravada em 1967, do disco solo do cantor baiano, lançado em 1968. Inspirada em instalação artística homônima de Hélio Oiticica, exposta em abril de 1967 na mostra intitulada Nova objetividade brasileira, feita no Museu de Arte Moderna do Rio de Janeiro (MAM-RJ). Além disso, uma das fontes de inspiração essenciais do movimento fora justamente o cinema, mais especificamente o filme Terra em transe, do diretor baiano Glauber Rocha, cujo impacto em Veloso é de importância sensível. À vista disso, pode-se dizer que, diferenciando-se parcialmente de interpretes como Basualdo (2007) e Süssekind (2007), há no texto de Duarte uma centralidade da música, tanto quanto a origem e rotinização, quanto da repercussão e consequências artísticas e culturais do tropicalismo.

O segundo caminho analítico de Duarte mostra-se quando o autor enxerga o movimento tropicalista como conjugação tensa entre tradição e modernidade. Conjugação que se dava sob o signo do paradoxo, visto que o que era novidade crítica pro- 
piciada pela modernidade transfigura-se em procedimentos domesticados e socialmente absorvidos até porque só assim poderia seguir adiante e disseminar-se (p. 12). Nessa equação musical, o termo tradicional seria representado pelo quinhão da música popular e sua imagem utópica de país, já que, desde o samba, ao menos, a vida musical desenrolou-se no cruzamento de elementos de classes sociais distintas. Alinhada à modernidade, vemos a pretensão vanguardista da tropicália, perseguindo desafios formais e experimentaçóes estéticas, nas quais conseguia conjugar experiências diversas. Dentre elas, destacam-se o movimento Música Nova, de Rogério Duprat e Júlio Medaglia, da poesia concreta de Haroldo e Augusto de Campos, das montagens fílmicas fracionadas de Jean-Luc Godard e Glauber Rocha e da radicalização de liçóes musicais aprendidas com a Bossa Nova, de João Gilberto.

É justamente com este último compositor que conseguimos entender que os termos da equação tropicalista anterior (moderno e popular) não são estanques, pois o projeto musical de Gil, Veloso e outros pretendia dar continuidade à linha evolutiva da canção popular brasileira, colocada em devir por João Gilberto (p. 93) e as mudanças radicais por ele executadas na música. Tais modificações joão-gilbertianas foram baseadas em certa racionalização formal na relação entre fala, batida no violão ${ }^{3}$ e a melodia, as quais permitiam a reavaliação do gosto, do passado musical brasileiro, além de sugerir programas e possibilidades musicais novas aos artistas vindouros. Mesmo assim, deve-se ponderar que, diferentemente de boa parte das obras vanguardistas do século XX, o impulso experimental associava-se à força popular da canção, dando-lhes proteção contra as exigências formais do público e lançando-o no mercado e na sociedade, contrariando o recuo construtivo modernista. ${ }^{4}$

A terceira escolha interpretativa do professor carioca seguiria um entendimento quase comum nos estudos sobre o tropicalismo e entre seus agentes, qual seja: este movimento deveria ser entendido como continuador da antropofagia, desenvolvida em primeira mão por Oswald de Andrade ${ }^{5}$. No entanto, Duarte (p. 119) inova ao argumentar que não foi somente o "Tropicalismo que se filiou à antropofagia, mas a antropofagia que, através dele, tornou-se na prática o que ela é hoje”. Ou, melhor dizendo, a tropicália náo deveria ser entendida como o alvo atingido pela flecha antropofágica posteriormente, e sim como "o arco que, pela ordem histórica do sentido, fez da antropofagia o que ela nunca tinha sido até então e nunca teria sido por si só” (p. 119).

Isso posto, fica a questão: não seria mais fidedigno apontarmos essa relação como uma espécie de uso feita pela tropicália e seus integrantes quanto à antropofagia ou, ao menos, náo seria melhor tencionar essa aproximação feita constantemente com poucas mediaçóes? Isso porque - emprestando o raciocínio de Lima (2012) quanto às diferenças entre a encenação pelo Teatro Oficina da peça $O$ rei da vela, de Oswald e a peça em si, bem como suas intenções políticas - as intenções políticas de Oswald de Andrade parecem, diversas vezes, ter mais afinidades com posiçóes expressas pela esquerda comunista, como em sua crítica ao imperialismo e à depravação burguesa, do que essa leitura de Duarte e outros autores fazem crer. Além disso, seguindo sugestões de Schwarz (2012b), se poderia mesmo ver tanto a antropofagia quanto a tropicália como programas estéticos do Terceiro Mundo. Todavia, enquanto na primeira o entrechoque entre modernidade e atraso figuram como promessa de um futuro alegre, na última, por seu turno, tal embate encarna o absurdo e o fracasso histórico como essências do Brasil (Schwarz, 2018).

Outro foco interpretativo importante do livro de Duarte é sobre a forma como a tropicália vê o Brasil no mundo. De acordo com ele, tal movimento teria gerado uma forma de pensamento sobre o contato do Brasil com o Ocidente tendo "em vista o seu subdesenvolvimento frente aos ganhos civilizatórios de origem europeia como a sua afirmação culturalmente singular no entendimento da vida” (p. 13). Mas isso não se constituiria em uma visão celebratória de nosso atraso (Schwarz, 2012a) e nem em uma inferiorização colonizada, e sim em uma crítica alegre ou alegria crítica própria ao Brasil. ${ }^{6} \mathrm{Tal}$ posicionamento fortalece, ainda, a vinculação feita anteriormente entre a antropofagia e a tropicália e sua visão sobre as particularidades nacionais.

Tendo como pano de fundo essa constelação conceitual, o filósofo carioca logra confeccionar uma organização em sua obra, a qual retoma em 
seus títulos categorias clássicas da cinematografia, a saber: close, plano médio e plano geral. Talvez numa tentativa de figurar em sua exposição as montagens e bricolagens caleidoscópicas da tropicália. No entanto, a maneira como é estruturada o livro não traz à baila a mesma experiência composicional radical do movimento artístico brasileiro, baseando-se numa organização cinematográfica um tanto tradicional. Contudo, essa estruturação ganha relevo em seu ensaio, pois, a partir desse enquadramento fílmico, pretende olhar detidamente o movimento tropicalista como componentes de um filme.

No close, se vê um personagem nítido e vinculado às diatribes autoritárias do cenário político nacional e seus resultados. No plano médio, constatam-se que a personagem em questão tem as vestes coloridas, destoando da sobriedade elegante da bossa nova, ao mesmo tempo que evidencia a linha evolutiva da música vanguardista nacional. Em plano longo, por seu turno, observam-se o rebento final da arte brasileira inaugurada com o modernismo de 1920, trazendo consigo a experimentação e atualização estéticas necessárias e uma reflexão crítica sobre a modernização à brasileira, isso tudo em chave ineditamente massificada e mercadológica. Entretanto, como já assinalamos, dentre as diversas escolhas interpretativas feitas por Duarte, enfatizaremos nesta resenha os legados quanto ao pensamento político e social logrados pela tropicália.

Conforme promete no começo do livro, Duarte debruça-se com vagar sobre os sentidos político-estéticos do LP Tropicália ou Panis et circencis, bem como sua vinculação ao contexto autoritário da época. De acordo com o autor, o nascimento do tropicalismo dataria já de 1967, momento dos discos individuais e apresentaçóes musicais em festivas televisivos de Caetano Veloso e Gilberto Gil. Contudo, o documento de coesão do grupo estendido seria justamente o lançamento do disco supracitado em julho de 1968. Nesse sentido, não deixa também de ser sugestiva a trajetória da própria denominação do movimento, muito mais aceita do que inventada pelo conjunto e colocada em circulação pelo jornalista Nelson Motta - grafada, porém, como tropicalismo.

De todo modo, a partir de análise detida de várias músicas, duas são as características marcantes da obra e que são trabalhadas por Duarte. A primeira diz respeito à construção alegórica - notada e trabalhada por boa parte da fortuna crítica - levada a cabo pelos artistas tropicalistas. Nesse registro, a exigência de totalização simbólica clássica, que pretendia representar o Brasil por completo, sai de cena e o central passa a ser um processo de fragmentação. Fragmentação assentada num acúmulo acelerado e tenso de imagens diversas e contraditórias, cujo intuito era expressar a "disfuncionalidade orgânica brasileira" (Venâncio Filho apud Duarte, 2018 , p. 32) e náo o mito do paraíso tropical. A segunda é o fato de a violência e a repressão político-policial da ditadura de 1964, fundo social em que os artistas estavam inseridos, passam a ser tema e forma das músicas presentes no LP de 1968. Prova disso são as cançôes "Miserere nobis" e "Enquanto seu lobo não vem", travejadas por tiros, sangue, censura e repressão. Ambos elementos marcam, no fundo, um movimento de radicalização estética e política experimentado pelos tropicalistas entre os anos de 1967 e 1968. O que levou, por exemplo, à recepção deveras negativa deles no III Festival Internacional da Canção da Globo e à sedimentação de uma camada de reflexividade e de consciência histórica anteriormente inexistente no grupo.

Entretanto, é preciso notar que essa radicalidade dos tropicalistas divergia sensivelmente do que pensava parte importante da esquerda sobre ser radical no período. Ao contrário dos artistas engajados e das músicas de protesto, à época a tropicália dispensava "a confiança teleológica em um futuro popular” (p. 47) e trazia à baila uma conjugação entre pessimismo sentimento com o qual problematizava alegoricamente a história - e alegria, ou um otimismo utópico, alicerçado justamente no pessimismo e não a despeito dele. Essa recusa ao dualismo transfigurava-se, segundo Duarte, numa postura vanguardista de tentar mudar a vida via arte, por meio da qual o tropicalismo convertia-se, além de uma experimentação musical, em "uma erotização do corpo, uma micropolítica e uma performance visual e discursiva” (p. 49), cujo ponto de fuga operava uma mudança de eixo da revolução para o da rebeliấo. Se em ambas a crítica à tradição é comum, na primeira teríamos um ideal fechado de futuro e uma centralidade da luta de classes; na segunda, por sua vez, o futuro abre-se 
para a pura indeterminação e os conflitos passam a ser vistos de maneira pulverizada nas diversas esferas da vida.

Ademais, deve-se atentar que essa rotação de eixo político teve por consequência outro deslocamento importante: o alvo das críticas não seriam mais as classes dominantes e o capitalismo, mas sim o ritual conservador proveniente das pequenas moralidades familiares, próprias de um conservadorismo pequeno burguês, tomado em sentido cultural e não econômico. Ou seja, no lugar da luta de classes, vê-se a ênfase numa luta intergeracional quanto aos costumes cotidianos, abrindo espaço, na esquerda, para questóes além da pobreza e exploração, como o machismo, a homossexualidade e a liberdade estética. Dessa feita, é possível atinar que o tropicalismo coloca em circulação, segundo Duarte, uma nova sensibilidade de esquerda, diversa da área mais nacionalista da canção nacional, imantada numa confiança inabalável no "povo" e dos marxistas, centrados na luta de classes e seus desdobramentos.

Diante do que foi dito até aqui, é viável afirmar que o livro em questão figura como uma das referências de estudo sobre a tropicália. Assim, é preciso reconhecer que o autor logra expor de forma até mesmo concisa os sentidos estéticos, políticos, culturais e sociológicos abertos pelo tropicalismo, conforme havia anunciado no princípio da obra. Não obstante, é necessário assinalar que a sua estruturação e exposição, por demais coesa, faz com que ruídos e dissonâncias do movimento fiquem, em boa medida, de fora. Fiquemos com um exemplo e dois casos. Ao apostar no potencial plenamente disruptivo do tropicalismo, ${ }^{7}$ o leitor pode não conseguir entender dois pontos sugestivos: em primeiro lugar, o fato de até hoje vários participantes do movimento serem figuras consagradas e de proa da indústria cultural brasileira; em segundo lugar, o acontecimento nada desprezível de Gilberto Gil ter virado Ministro da Cultura (2003-2008) e, por conseguinte, ter participado ativamente da gestão estatal. Em outras palavras: se a rebeldia política e a revolução formal eram as características essenciais desse movimento, como entender a sua celebração pela establishment ou pelos conglomerados musicais e a participação deles no sistema político nacional?
No mais, para aqueles que não estão ocupados apenas em nascer e morrer, o livro vem em boa hora.

\section{Notas}

1 O disco reuniu Caetano Veloso, Gilberto Gil, Tom Zé, Gal Costa, Os Mutantes, com arranjos de Rogério Duprat, além da participação de Nara Leão, Torquarto Neto e José Carlos Capinam.

2 Note-se que essas interpretaçóes voltam-se contra o ensaio "Cultura e política, 1964-1969", de Roberto Schwarz (2008), no qual o crítico enxerga na tropicália o encapsulamento da experiência de um progresso que repóe o atraso.

3 É perceptível a centralidade da "batida de João Gilberto" entre seus colegas e estudiosos da bossa nova, a qual, logrou resolver o "hibridismo rítmico do samba-jazz ou do jazz-samba, dissolvendo-o em um estilo original" (Garcia, 1999, p. 98).

4 Conforme Gilberto Gil disse certa vez: "E nós estamos aqui para vender. Não fomos nós que fizemos de nossa música mercadoria. Mas ela só penetra quando vendida" (Gil e Veloso, 2008, p. 130).

5 Outra posiçấo interessante, e que tem ressoado nos estudos sobre antropofagia e tropicália, sustenta uma leitura do primeiro a partir do arcabouço do perspectivismo ameríndio de Viveiros de Castro (2011 apud Azevedo, 2016).

6 Tal passagem nos faz lembrar da interpretação sobre o Brasil defendida por Wisnik (2008), a qual conjugaria tanto visóes críticas (veneno) e visôes generosas (remédio) em relação ao país.

7 Nesse sentido, ver a questáo colocada por Duarte (p. 73): "Não havia espaço para ele [tropicalismo] no país de então. Haverá hoje?".

\section{BIBLIOGRAFIA}

AZEVEDO, Beatriz. (2016), Antropofagia: Palimpsesto Selvagem. São Paulo, Cosac Naify.

BASUALDO, Carlos. (2007), "Vanguarda, cultura popular e indústria cultural no Brasil", in C. Basualdo, Tropicália, São Paulo, Cosac Naify.

COELHO, Cláudio. (1989), "A tropicália: cultura e política nos anos 60". Tempo Social, 1 (2): 159-176. 
DUNN, Christopher. (2009), Brutalidade jardim: a tropicália e o surgimento da contracultura brasileira. São Paulo, Editora Unesp.

DUARTE, Pedro. (2014), Palavra modernista: vanguarda e manifesto. Rio de Janeiro, Casa da Palavra.

FAVARETTO, Celso. (2007), Tropicália, alegoria, alegria. 4. ed. Cotia (SP), Ateliê Editorial.

GARCIA, Walter. (1999), Bim bom. São Paulo, Paz e Terra.

GIL, Gil \& VELOSO, Caetano. (2008), "Debate da FAU", in S. Cohn e F. Coelho, Tropicália, Rio de Janeiro, Beco do Azougue.

HOLLANDA, Heloisa Buarque de \& GONÇALVES, Marco Antônio. (1982), Cultura e participação nos anos 60. São Paulo, Brasiliense.

LIMA, Bruna Della Torre de Carvalho. (2012), Vanguarda do atraso ou atraso da vanguarda? Oswald de Andrade e os teimosos destinos do Brasil. Dissertação de mestrado, São Paulo, FFLCH-USP.

POLARI, Alex. (1982), Em busca do tesouro. Rio de Janeiro, Codecri.

RIDENTI, Marcelo. (2014), Em busca do povo brasileiro. 2. ed. São Paulo, Editora Unesp.

SANTIAGO, Silviano. (1977), "Fazendo perguntas com o martelo", in G. Vasconcellos, Música popular: de olho na fresta, Rio de Janeiro, Graal.

SANTIAGO, Silviano. (1982), Vale quanto pesa. Rio de Janeiro, Paz e Terra.

SCHWARZ, Roberto. (2008), "Cultura e política, 1964-1969", in R. Schwarz, O pai de família e outros estudos, São Paulo, Companhia das Letras.

SCHWARZ, Roberto. (2012a), Nacional por subtração, in R. Schwarz. Que horas são? São Paulo, Companhia das Letras.

SCHWARZ, Roberto. (2012b), "Verdade tropical: um percurso de nosso tempo", in R. Schwarz, Martinha versus Lucrécia: ensaios e entrevistas, São Paulo, Companhia das Letras.

SCHWARZ, Roberto. (2018), "Roberto Schwarz reflete sobre quatro tentativas de modernizaçáo do Brasil". Entrevista concedida a B. D. T. C. Lima e M. G. Garcia. Folha de S.Paulo, Ilustríssima, 21 jul.
SÜSSEKIND, Flora. (2007), "Coro, contrário, massa: a experiência tropicalista e o Brasil de fins dos anos 60", in C. Basualdo, Tropicália, São Paulo, Cosac Naify.

TINHORÃO, José Ramos. (1991), Pequena história da música popular: da modinha à lambada. 6. ed. São Paulo, Art.

VASCONCELLOS, Gilberto. (1997), Música popular: de olho na fresta. Rio de Janeiro, Graal.

VELOSO, Caetano. (2017), Verdade tropical. 3. ed. São Paulo, Companhia das Letras.

WISNIK, José Miguel. (2008), Veneno remédio: o futebol e o Brasil. São Paulo, Companhia das Letras.

(cc) BY Creative Commons License This is an Open Access article distributed under the terms of the Creative Commons Attribution License which permits unrestricted use, distribution, and reproduction in any medium, provided the original work is properly cited. 